\title{
BIM INNOVATION CAPABILITY PROGRAMME OF IRELAND
}

\author{
Alan Hore ${ }^{1}$, Barry McAuley ${ }^{2}$ and Roger West ${ }^{3}$
}

\begin{abstract}
The Irish Government has requested that Enterprise Ireland, an organisation responsible for the development and growth of Irish enterprises in world markets to actively promote the use of BIM in Ireland. This promotion has taken the form of an opportunity for Enterprise Ireland clients to apply for a grant under their BIM Enable and BIM Implementation schemes and also through their funding of the BIM Innovation Capability Programme (BICP) of Ireland. The BICP is a two-year project (2016-2018) which seeks to capture the capability of the Irish Construction Industry and the Higher Education Institutes to respond to the increased requirement for BIM in Ireland. One of the primary responsibilities of the BICP research team is to collate data to assist the Irish National BIM Council (NBC) in the formulation of a National BIM Roadmap. To achieve this a global and local BIM study was undertaken in 2016. This involved extensive desk-top based research exploring the value proposition behind what governments and professional bodies are doing to advance BIM in their respective countries. The research identified a number of common themes or pillars that Ireland will need to further address before a roadmap is formally disseminated. After exploration of these pillars, within an Irish context, it was found that despite a lack of standards and contractual frameworks, it has not prevented the industry from deploying BIM on Irish projects
\end{abstract}

Keywords: BIM, Irish Roadmap, Public Works, BIM Innovation Capability Programme

\section{INTRODUCTION}

The recent World Economic Forum (WEF, 2016) reported that most other industries have undergone tremendous changes over the last few decades, while the construction sector has been hesitant about fully embracing the latest technological opportunities. WEF (2016) acknowledges that this is beginning to change thanks to digitalization, innovative technologies and new construction techniques, such as Building Information Modelling (BIM). BIM is now seen as a core technology at the forefront of this transformational change with the global market for BIM expected to reach $\$ 7,946$ million by 2020 (Daedal Research, 2016). Governments across the globe are increasingly recognising the efficiencies that can be gained with this transformational change. Learning from leading jurisdictions, governments who are embarking on the transformational journey have been convinced that the strategic use of BIM can support a leaner more innovative construction sector thus addressing declining productivity (Kelly et al., 2013).

1 BICP Principal Investigator, School of Surveying and Construction Management, Department of Built Environment, Dublin Institute of Technology, Ireland, alan.hore@dit.ie

2 BICP Postdoctoral Researcher, School of Surveying and Construction Management, Department of Built Environment, Dublin Institute of Technology, Ireland, bmcauley@cita.ie

3 BICP Associate Supervisor, Department of Civil, Structural and Environmental Engineering, Trinity College, College Green, Dublin 2, Ireland, rwest@tcd.ie 
In an Irish context, the second national survey to measure the level of BIM adoption in Ireland revealed that $76 \%$ of respondents possessed confidence in their organisation's BIM skills and knowledge. The Construction IT Alliance (CitA), which has been promoting the digital agenda in Ireland since 2002, has played a key role in achieving these figures. In 2015 the alliance secured funding from Enterprise Ireland for the BIM Innovation Capability Programme (BICP). The BICP seeks to capture the capability of the Irish Construction Industry and the Higher Education Institutes (HEIs) to respond to the increased requirement for BIM on Irish construction and engineering projects. An explicit ingredient of the BICP involves conducting a comprehensive review of both global and local BIM adoption initiatives. The goal of this research is to assist the National BIM Council (NBC) of Ireland to develop a national road map in 2017 to optimise the successful implementation of BIM Level 2 and beyond. This paper contains the findings and recommendations from these two studies

\section{METHODOLOGY}

The methodology was twofold, with an initial desk-top based research exploring existing literature on global BIM adoption. The authors where interested to examine what key areas each country has addressed in order to ensure the correct foundations where in place for their current or proposed roadmap. Further clarification was sought with regard to countries which are similar to Ireland in BIM maturity and what initiatives are in place to further BIM growth in those countries. The findings from each country were crossreferenced and key themes established based on common practices for a successful roadmap. The findings were then assessed in relation to Ireland's current maturity within each area.

\section{BICP GLOBAL BIM STUDY}

The global BIM study reviewed the status of BIM in each of twenty-seven counties from across five different continents (Hore et al., 2017). In carrying out this initial scoping study researchers were keen to identify three key ingredients in each instance. This comprised information within each country with regards to authorisation to mandate the use of BIM on public sector projects, the key champions involved that were responsible for promoting this mandate and any noteworthy publications. This section will provide a brief overview of BIM maturity in each of the five continents reviewed.

\subsection{Europe}

From an EU perspective a number of countries have initiated national programmes to promote BIM capability. The European Commission recently awarded the EU BIM Task Group funding for two years (2016-2017) to deliver a common European network aimed at aligning the use of BIM in public works.

In the UK a Level 2 BIM programme has been mandated since 2016. The UK government's primary value proposition was to align this initiative with a measurable reduction in capital costs, delivery time and carbon usage. The UK has developed, in tandem with its BIM initiative, a suite of connected frameworks and guidelines. Scotland launched a Level 2 BIM Implementation programme in 2015, stipulating that BIM Level 2 would become a requirement by 2017 on projects over a threshold of $£ 4.32 \mathrm{~m}$. The Scottish Government have introduced a BIM Level 2 Grading Tool which helps one to understand when to adopt BIM Level 2 and the BIM Compass, which is to assess one's BIM capability. 
The French Government are to deploy BIM within the housing sector on 500,000 houses by 2017. The Le Plan Transition Numérique dans le Bâtiment task group is responsible for the French Roadmap. In Germany a number of high profile jobs have run significantly over budget which has led to the establishment of the Planen-bauen 4.0 limited company which will guide and steer the implementation of BIM towards a 2020 mandate.

Recently the Italian Standard body (UNI) published parts 1, 4 and 5 of the National UNI 11337. These standards address the required digital information management processes for building. Spain will also introduce a BIM mandate in March 2018 and further mandatory use in infrastructure projects by July 2019. A steering committee called Comisión para la Implantación de la Metodología BIM has been set up to promote BIM.

Scandinavian countries have been leading the BIM agenda for a number of years and have seen significant benefits. In Finland the Confederation of Finnish Construction Industries decided in 2002 that BIM would be a core element of its proposed changes to the sector. Senate Properties has mandated since 2007 for all design software packages to pass Industry Foundation Class (IFC) Certification in accordance with the requirement in its BIM guidelines. BIM has been in operation in Denmark for a number of years when in June 2011 the Danish Parliament extended the mandatory adoption of BIM to all local and regional projects worth over $€ 2.7$ million, while central government projects had a lower threshold of $€ 677,000$. The Norwegian government established its national mandate to reduce errors, improve coordination, increase the energy efficiency of its buildings and in general gain efficiencies. A joint statement which set out particular requirements for all project participants to use open standards by July 2016 was signed by a number of large public sector clients. The BIM Alliance Sweden published a BIM guideline, called 'BIM Standardiseringsbehov' to assist in promoting BIM adoption. Five public companies are collaborating to establish demands and standards regarding BIM adoption.

The Netherlands set up the Building Information Council as part of the Rijkswaterstaat highways and waterways BIM programme, so as to improve quality, continuity and international competitiveness of the Dutch building industry in 2012. A few open BIM standards have been successfully adopted to date, including COINS. The Czech Republic are just beginning to use BIM technologies and released the Czech BIM Handbook in 2013. An Open BIM guide for Switzerland has been recently published which helps users develop a BIM methodology in partnership with existing standards of the Swiss Society of Engineers and Architects.

\subsection{North America}

BIM in the USA has seen widespread adoption by large public owners, including the General Services Administration and the U.S. Army Corps of Engineers, both requiring BIM deliverables on all major projects. The Veterans Affairs Office of Construction and Facilities Management, New York City Department of Design and Construction and the State of Ohio BIM Protocol all deploy BIM mandates in their respective States or departments. Other public sector mandates include the State of Tennessee Office, Texas Facilities Commission, State of Maryland and Washington D.C. Public Schools, and State of Wisconsin. The National BIM Standard-United States provides consensus-based standards through referencing existing standards, documenting information exchanges and delivering best business practices.

The Institute for BIM in Canada (IBC) is to lead and facilitate the coordinated use of BIM in the design, construction and management of the Canadian built environment. The IBC have created a Canadian Roadmap for Lifecycle BIM in the Canadian AEC sector. 
Some of the IBC ongoing projects include a three-volume document titled BIM Practice Manual which will assist those firms across Canada which are interested in adopting BIM.

\subsection{South America}

Brazil's National Department of Transport Infrastructure is embracing BIM in the hope of it assisting in achieving a 30\% cost savings across the building lifecycle. The Brazilian AEC sector has only recently started BIM implementation, and the companies which have invested in this initiative in the past few years belong to the private sector. Souza et al. (2013) discuss how a number of Brazilian institutions have been developing study and work groups aiming to discuss the implementation of BIM and to promote its concept within the AEC community. In 2014 Dr Mohamad Kassem and BIM expert Professor Sergio Leusin created a report to present to Brazilian policy makers with conclusions and recommendations for BIM implementation in the country.

The Chilean government have introduced a BIM Plan which spans 10-years and seeks to achieve the requirement of BIM for public projects by 2020, and tentatively the requirement of BIM for private projects by 2025. The BIM Forum Chile is the main technical reference and meeting point in Chile around BIM, generating projects, activities and standards that add value to businesses. To achieve this a number of working groups have been created which are based around standardization and technology transfer.

\subsection{Asia}

Within Asia, the Singapore Building and Construction Authority had a roadmap for BIM that pushed its construction industry to be using it widely by 2015. The government's long term goal is to create a highly integrated and technologically advanced construction sector. A second BIM roadmap has been realised to further productivity within the public sector.

In China the Ministry of Housing and Urban-Rural Development's 12th National FiveYear Plan has requested the use of BIM. The China BIM Union have helped develop the Chinese National Unified Standard for BIM along with a series of standards for P-BIM (Practice-based BIM) and data exchange for specific tasks.

The Hong Kong Construction Industry Council Working Group issued the Roadmap for BIM Strategic Implementation in 2014. The roadmap outlines 17 initiatives, under 9 areas, to achieve industry-wide implementation of BIM. The HKIBIM BIM Standard establishes a process for adopting BIM on building projects. Various Universities and Colleges are providing a total of 19 BIM courses as part of their degree programmes.

\subsection{Oceania}

The McGraw Hill Smart Market Report (2014) for the business value of BIM in Australia and New Zealand details that despite BIM being relatively new in these countries, there is widespread recognition to its value. BIM in Australia is gaining traction and in some areas, such as, the Department of Planning, Transport and Infrastructure, BIM guidelines have been developed for government agencies, consultants and contractors, with the New South Wales' Health mandating BIM deliverables on all projects over $\$ 30$ million. An independent statutory body, Infrastructure Australia, released its new 15-year plan and BIM is highlighted as a recommendation to encourage strategic and integrated planning.

At present despite no mandate the BIM Acceleration Committee in New Zealand, in an effort to develop more efficient work processes, has produced the New Zealand BIM Handbook. The BIM Handbook provides a solid framework for deciding whether or not to use BIM, with a total of 21 defined uses. 


\subsection{Middle East}

Within the Middle East the UAE expect to record over the next cycle of its construction boom an estimated $\$ 30$ billion spend. This has seen Dubai Municipality in 2013 issuing a circular mandating BIM for specified architecture and MEP works in the Emirates for buildings over 40-storeys. In July 2015 an updated circular was issued which detailed Dubai Municipality's intent to expand the usage of BIM on buildings above 20 floors.

The landscape of Qatar is changing rapidly with a proliferation of mega projects underway as part of its National Vision for 2030. The nature and size of the projects means that Qatar has turned to BIM to facilitate its ambitious building schedule, leading to the formation of the Qatar BIM Guidelines Focus Group.

\section{7 buildSMART}

A common theme within countries seeking to adopt BIM is the presence of buildingSmart which have been in the forefront of implementing BIM by developing and maintaining the IFC platform. Presently there are eighteen buildingSMART Chapters globally. Examples of buildingSMART Chapters include buildingSMART Norway who have released a BIM Guideline database and buildingSMART Singapore who have also developed a library of design objects as well as collaboration guidelines

\subsection{Key Pillars}

Following the initial scoping exercise a number of common themes became very evident in the countries where BIM programmes were currently under development or in their formal implementation phase. Based on these recurring themes in successful international BIM programmes, the BICP team recommended that a number of BIM enablers be adopted by the NBC in June 2016. Tables 1 details the key findings. A principal enabler to a proposed road map should include a strong and solid partnership between government and industry.

\section{BICP IRISH BIM STUDY}

The BICP Irish BIM study builds on the findings from the BICP Global BIM Study by providing an in-depth review of BIM in Ireland with regards to each identified pillar.

\subsection{Procurement routes and BIM Guidelines}

Ireland's contractual landscape is aligned with the Capital Works Management Framework which consists of a suite of fixed priced public sector contacts. These contracts have proved contentious and, in a review of their performance, a medium term strategy was recommended in respect to BIM. This strategy describes BIM as a powerful risk management tool that also offers opportunities to move the construction of buildings from the building site to off-site fabrication.

Table 1: BIM Pillars for implementation in Ireland based on the global study

\begin{tabular}{|l|l|}
\hline Key Themes & Findings \\
\hline Procurement & $\begin{array}{l}\text { The alignment of the various contractual procurement methods in the light of the } \\
\text { requirements for more collaborative work-practices. This requires a review of } \\
\text { managing risk, intellectual property, insurance and warranty requirements for } \\
\text { clients, consultants and contractors. }\end{array}$ \\
\hline
\end{tabular}




\begin{tabular}{|l|l|}
\hline BIM Guidelines & $\begin{array}{l}\text { These guides provide industry and government clients, consultants and constructor } \\
\text { on collaborative working, open standards and general alignment with global best } \\
\text { practice. }\end{array}$ \\
\hline $\begin{array}{l}\text { Training and } \\
\text { Education }\end{array}$ & $\begin{array}{l}\text { Development and roll out a national awareness programme for governmental } \\
\text { clients, the development of national BIM curriculum, vocational training and } \\
\text { professional development. }\end{array}$ \\
\hline $\begin{array}{l}\text { Process Data } \\
\text { Exchange }\end{array}$ & $\begin{array}{l}\text { Adoption of best practice in respect to open BIM data exchange that will support } \\
\text { collaborative working across the project life cycle from early design inception to } \\
\text { maintenance and operational phases. }\end{array}$ \\
\hline $\begin{array}{l}\text { Regulatory } \\
\text { Framework }\end{array}$ & $\begin{array}{l}\text { Establishment of a regulatory mechanism or order that requires planners, regulatory } \\
\text { bodies, local government and government agencies and departments to require the } \\
\text { use of BIM protocols and open standards on all or specific centrally funded projects }\end{array}$ \\
\hline Pilot Projects & $\begin{array}{l}\text { Many countries have identified pilot projects, in which to "learn", "test" and verify } \\
\text { the readiness of the above programmes in an economy wide basis. }\end{array}$ \\
\hline
\end{tabular}

In 2016 Enterprise Ireland and CitA published its second Digital Transition Survey which showed an increase in the application of the CIC BIM protocol from $20 \%$ to $35 \%$.

A number of countries have developed their own BIM guidelines e.g. Czech BIM Handbook, Norwegian BIM manual, New Zealand BIM Handbook, etc. While no national Irish guidelines exist presently there have been recent publications from organisations, such as, the Royal Institute of Architects Ireland (RIAI) which has produced templates for an Irish focused BIM Execution Plan and Employers Information Requirements.

\subsection{Training and Education}

A key pillar required for any successful BIM strategy is the upskilling of professionals at all levels of the supply chain. All countries reviewed are, to some extent, providing BIM training programmes. Despite the absence of a BIM mandate in Ireland, there is still a high level of training and education services available. Most of the Higher Education Institutes (HEIs) are offering BIM courses to varying degrees. In December 2016, the BIM Academic Forum in Ireland (BAFI) was established with the core purpose for academia to come together to collectively promote the teaching of BIM in Ireland. BAFI is largely modelled on the BAF initiative in the UK.

A key champion of BIM in Ireland has been CitA which, as a result of its partnership with professional institutions, has provided over 50 industry-focused BIM workshops since 2010. Further to this, CitA held international conferences in the form of BIM Gatherings in both 2013 and 2015, with the 3rd Gathering scheduled for November 2017. CitA has also hosted a Technology Challenge in 2014 which was a 4-day studio-based workshop and 1 day symposium. In 2016 CitA held the Irish BIM Innovation Awards which showcased 13 exemplar projects within Ireland.

\subsection{Process data Exchange}

In 2016 a milestone in BIM in European standardization was reached with the adoption of the first three European Standards. Despite no set standards or contractual guidelines that represent a customised Irish solution there is still evidence of using existing international standards.

With regards to standards, the 2016 Irish Digital Transition Survey shows an increase in adoption of PAS1192: 2 and PAS1192:3 from 33\% and 35\% to 55\% and 45\% in 2015 and 2016 respectively. Ireland has recently set up a National Mirror Technical Committee to follow the development of BIM standards in EU under CEN TC 442. 


\subsection{Regulatory Framework}

Despite the absence of an Irish Government BIM mandate there has been a number of noteworthy publications, such as the Construction 2027 report, which contained strong recommendations that industry organisations promote the use of BIM. An action proposed within the Government Action Plan for Jobs 2017 states that the Office of Government Procurement (OGP) prepare a strategy for the adoption of BIM across the public capital programme and to mandate the manner in which it is to be adopted across the public sector. The OGP have responded through a positional paper by setting different target dates ranging from 12 - 48 months for projects to adopt BIM. These project range from Band 1 which are of low complexity, such as low density housing projects, to Band 5 which are complex projects with a specialist operation and maintenance regime, such as acute hospitals. The NBC will work in cognisance of this positional paper to ensure any operational roadmap is aligned with the needs of the public sector.

\subsection{Pathfinder Projects}

Pathfinders projects, such as Cookham Wood in the UK, have enabled the documentation of key lessons learned that will assist future projects in their transition to BIM. The BICP team surveyed a community of BIM managers in Q1 2017. A total of 90 professionals with a particular responsibility for BIM in Ireland were targeted in the study, and 47 responses were received. One of the key aims of this survey was to identify what projects currently deploy BIM tools and processes in Ireland. A good variety of projects were identified by the respondents. This included schools, student accommodation, fit out projects, commercial development, hospitals, third level, data centres, social housing, primary care centres, hotels, social housing, primary care centres, pharmaceutical and food manufacturing facilities. Over 50 BIM projects were reported by the respondents signifying that BIM projects are becoming more mainstream in Ireland in 2017.

Current public sector projects working with BIM processes and technologies include the $€ 135$ million courts and school bundles. The National Development Financial Agency continue to promote the use of BIM technologies for public works projects. The Health Service Executive has also requested BIM for part of its tender requirements for the $€ 1$ billion National Children's Hospital. Transport Infrastructure Ireland is exploring the possibilities of using BIM for the Metro North. The Irish BIM Innovation Awards recently showcased thirteen projects in different stages of development where BIM was extensively deployed. These projects currently represent available options that could possibly represent a vehicle for a Irish pathfinder project.

\section{CONCLUSION}

The practical implications of this study is assisting the NBC in formulating their road map which has been broken into the six key sub packages consisting of Leadership, Procurement, Standards, Training and Education and Transition. Each one of these packages must outline a vision and propose how this is to be executed. The findings from both the BICP Global and Irish BIM studies have provided a valuable reference point with regards to providing data on the current situation and key gaps in place for each sub package. The BICP will continue to work with both public and private sector bodies, HEIs and the NBC to provide the key data that will assist in fulfilling their BIM implementation agenda. 


\section{REFERENCES}

Bernstein, H. M., Jones, S. A., Russo, M. A., Laquidara-Carr, D., Taylor, W., Ramos, J., and Pineda, R. (2015) The Business Value of BIM in Australia and New Zealand, SmartMarket Report, McGraw Hill Construction.

BIM Innovation Capability Programme, Information available at < www.bicp.ie>

BICP Research Team (2017) Engaging with the BIM Community, available at< http://www.bicp.ie/bim-managers-ireland/>.

BICP Research Team (2017) Assessing the Current Position and Associated Challenges of BIM Education in Irish HEIs, available at http://www.bicp.ie/bicp-workgroups/.

Construction Industry Federation ( 2016) Constructing Ireland 2027 - A 10 year vision for the construction industry, The CIF Annual Conference, available at < www.cifconference.ie/>.

Construction IT Alliance, Information available at $<$ www.cita.ie $>$

Daedal Research (2016) Global BIM Market: Size, trends and Forecasts (2016-2020), available at www.researchandmarkets.com/research/2mjrbq/global building.

Department of Jobs, Enterprise and Innovation (2017) Action Plan for Jobs 2017, Irish Government.

Hore A., McAuley, B. and Hunt, L. (2016) Industry Leaders in Construction - Transition to Digitisation 2016, available at < www.bicp.ie/digital-transition-survey/>.

Hore, A, McAuley, B. and West, R. (2017) The BICP Global BIM study, available from < www.bicp.ie/bicp-global-bim-study>.

Jung, W. and Lee, G., (2015) The Status of BIM Adoption on Six Continents, International Journal of Civil, Environmental, Structural, Construction and Architectural Engineering, 9, 415-419.

Kelly, G., Serginson, M., Lockley, S., Dawood, N. \& Kassem M. (2013) BIM for facility management: a review and a case study investigating the value and challenges, Proceedings of the 13th International Conference on Construction Applications of Virtual Reality, 30-31 October, London, UK.

Office Government Procurement (2017) A Public Sector BIM Adoption Strategy: A GCCC positional paper, Government Construction Contracts Committee.

McGraw Hill Construction (2014), The Business Value of BIM in Australia and New Zealand: How Building Information Modeling is Transforming the Design and Construction Industry, Smart Market Report.

National BIM Council, Information available at $<$ www.nbcireland.ie/ $>$.

Research and Markets (2015) Building Information Modelling Market - Analysis and $\begin{array}{llllll}\text { Forecast } & \text { to } & 2015 & - & 2020, & \text { available }\end{array}$ www.researchandmarkets.com/research/st9k8v/building.

Rooney, K. (2015) BIM Education - Global - 2015, Update Report, NATSPEC.

Smith, P. (2014) BIM Implementations - global strategies. Procedia Engineering, Vol 85,

Souza, F., Wyse, M. and Melhado, B. (2013) The Brazilian Design Manager Role and Responsibilities after the BIM Process Introduction, Proceedings of the World Building Congress, Brisbane, Australia, 5-9th May.

World Economic Forum (2016) Shaping the Future of Construction A Breakthrough in Mindset and Technology, World Economic Forum. 